\title{
SISTEM ABSENSI ONLINE BERBASIS WEB DENGAN QR CODE SECARA REAL TIME MENGGUNAKAN ALGORITMA VIGENERE CIPHER
}

\section{WEB-BASED ONLINE ATTENDANCE SYSTEM WITH QR CODE IN REAL TIME USING VIGENERE CIPHER ALGORITHM}

\author{
Dicky Prasetyo ${ }^{1}$, Iskandar Fitri², Albaar Rubhasy ${ }^{3}$ \\ Program Studi Informatika, Fakultas Teknologi Komunikasi dan Informatika, \\ Universitas Nasional ${ }^{1,2,3}$ \\ kymoura09@gmail.com
}

\begin{abstract}
In this day and age technology is developing very rapidly, of course in terms of the presence of workers. So there are benefits in the current situation. Attendance for now is done physically or manually. This is certainly less effective and efficient and causes the attendance information obtained to be inaccurate, so a system is needed that makes attendance feasible and productive for all agencies. Therefore, a web-based online attendance system was designed using the Vigenere Cipher Algorithm and the R\&D (Research and Development) method with the PHP programming language codeigniter framework and using the MySQL database. The system was formed with the aim of facilitating the process of employee attendance as well as recapitulation and attendance reports by the administration. The system is made using QR Code technology so that attendance can be done in a similar system. The system created produces several features in the form of users features, checking $Q R$ codes for attendance attendance, generating $Q R$ codes from each employee card, recapitulation and attendance reports on the system, and employee data in the form of employee names, positions, work shifts and work location placements.
\end{abstract}

Keywords: Attendance, Vigenere Cipher Algorithm, $R \& D, Q R$ Code, webcam.

\section{ABSTRAK}

Di masa sekarang ini teknologi berkembang sangat pesat, tentunya dalam hal kehadiran para pekerja. Sehingga ada manfaat di situasi sekarang ini. Absensi untuk sekarang ini dilakukan secara fisik atau manual. Hal ini tentunya kurang efektif dan efisien serta menyebabkan informasi kehadiran yang didapat kurang tepat, sehingga diperlukan sistem yang menjadikan absensi layak dan produktif bagi semua instansi. Karena itu, dirancanglah sistem absensi online berbasis web menggunakan Algoritma Vigenere Cipher dan metode R\&D (Research and Development) dengan framework codeigniter bahasa pemrograman PHP serta menggunakan basisdata MySQL. Sistem dibentuk dengan tujuan memudahkan proses absensi karyawan serta rekapitulasi dan laporan kehadiran oleh administrasi. Sistem dibuat dengan menggunakan teknologi QR Code agar dapat dilakukan absensi di sistem yang serupa. Sistem yang dibuat menghasilkan beberapa fitur berupa fitur users, memeriksa kode QR untuk absensi kehadiran, generate kode QR dari setiap kartu karyawan, rekapitulasi dan laporan kehadiran pada sistem, dan data-data karyawan berupa nama karyawan, jabatan, shift kerja dan penempatan lokasi kerja.

Kata Kunci: Absensi, Algoritma Vigenere Cipher, R\&D, QR Code, Webcam.

\section{PENDAHULUAN}

Absensi adalah rutinitas yang dilaksanakan setiap orang untuk menunjukkan bahwa dirinya hadir atau tidak dalam institusi. Absensi diidentifikasi dengan pemanfaatan kehadiran yang dikendalikan oleh masing-masing organisasi atau perusahaan (Lengkong et al., 2016).
Penerapan yang dilakukan dalam institusi diperlukan oleh kedua pengguna yaitu, administrator yang dalam hal ini hanyalah pengelola sistem dan karyawan sebagai pengguna sistem absensi. Selain itu, absensi sebagai insentif tambahan bagi para pekerja.

Kondisi absensi saat ini pada organisasi atau perusahaan tertentu 
masih dilakukan secara fisik dan ada pula yang sudah diprogramkan atau otomatis, khususnya melalui absensi finger print dan untuk yang manual dengan tanda pada lembar absensi. Institusi yang memanfaatkan absensi manual, tentunya kurang efisien dan efektif dalam kehadiran, informasi yang harus disajikan dan dihitung secara manual, tentunya sangat menyulitkan dan memakan waktu yang lama. Selain itu, pengelola juga akan kebingungan saat melapor kepada atasan dengan lembar absensi yang tidak terhitung jumlahnya.

Berbagai jenis sistem kehadiran digunakan dalam berbagai keadaan seperti sekolah dan perusahaan, yaitu sistem berbasis web yang dapat digunakan sebagai pengganti yang tidak hadir (Puput et al., 2019). Dalam penelitian terdahulu, penggunaan sistem QR Code untuk absensi dalam institusi dan pendidikan dapat memberikan reaksi cepat serta memudahkan penggunanya dalam melakukan rutinitas kehadiran pada institusi terkait atau lembaga pendidikan. Penerapan dilakukan cara scanning QR Code dengan menempelkan QR Code pada kamera yang tersedia oleh sistem dan secara otomatis pengguna akan dinyatakan hadir oleh sistem (Patel et al., 2019)(Rhomadhona, 2018). Selain itu, penelitian terkait dengan kehadiran yaitu sistem absensi berbasis QR Code yang memerlukan verifikasi pengguna menggunakan RFID finger print. Pengujian aplikasi yang dilakukan dengan cara memindai QR Code yang berfungsi sebagai identitas user serta verifikasi user menggunakan sidik jari atau pengenalan suara (Kumar \& Kareemulla, 2017).

Berdasarkan latar belakang di atas, peneliti memiliki inisiatif pada pengambilan titik fokus pada sistem absensi dengan QR Code sebagai alat bantu kehadiran, dikarenakan karyawan dapat dengan mudah melakukan kehadiran sesuai jadwal dan dapat melakukan absensi yang terhitung sebagai kehadiran tersebut. Selain itu, konfigurasi modifikasi pada desain sistem memiliki fitur cetak kartu identitas dengan QR Code sebagai alat bantu kehadiran karyawan dan menu sebagai pengembangan dari desain yang dirancang agar memudahkan users atau pengguna dalam menggunakan sistem tersebut. Sistem absensi yang dirancang oleh peneliti adalah sistem absensi basis web dan absen dilaksanakan dengan cara scanning QR Code pada kartu identitas di setiap karyawan. Sistem yang dicapai dapat menghemat waktu dan usaha yang dilakukan oleh setiap karyawan dalam hal kehadiran di waktu kerja serta memudahkan pengelola sistem dalam melakukan tugasnya yaitu, membuat rekapitulasi dan laporan kehadiran yang nantinya akan diserahkan kepada atasan.

\section{METODE}

Penggunaan metode yang digunakan dalam merancang "Sistem Absensi Online Berbasis Web Dengan QR Code Menggunakan Algoritma Vigenere Cipher" adalah metode Research and Development (R\&D) adalah metode ini merupakan metode yang menghasilkan produk-produk serta melakukan uji validitas dan ke efektifan (Patta \& Suhartono, 2017). Isi-isi pokok penelitian pada metode R\&D meliputi :

\section{Analisis Kebutuhan Sistem}

Pada penelitian ini peneliti menggunakan beberapa sistem pendukung perangkat keras (hardware) dan perangkat lunak (software) untuk merancang bangun sistem aplikasi absensi berbasis web, diantaranya:

\section{Hardware}

Personal Computer (PC) dengan spesifikasi sebagai berikut: 
1. Processor intel core i5 gen 8 1.8Ghz

2. Random Access Memory 4GB

3. Harddisk Drive $1 \mathrm{~TB}$

4. VGA Radeon ATI 2 GB

5. System type 64-bit Operating System

6. Webcam sebagai komunikasi antara sistem dengan QR Code.

\section{Software}

Software yang digunakan dalam membuat rancangan aplikasi absensi berbasis web, diantaranya yaitu:

1. XAMPP versi 3.2.4

2. Visual Studio Code

3. Web browser

\section{Perencanaan Sistem}

Sistem menyajikan data karyawan beserta nama karyawan, jabatan, dan lokasi penempatan kerja yang menjadi dasar identitas pada kartu. Aplikasi menyediakan fitur cetak kartu identitas disetiap karyawan berisi identitas karyawan dan QR Code yang digunakan pada saat pengambilan kehadiran dengan cara scanning mengambil data id dari setiap karyawan serta waktu absensi. Scanning dilakukan dengan kamera laptop (webcam) yang terkonfigurasi dengan sistem yang dirancang.

\section{Pengembangan}

\section{Perancangan Use Case Diagram}

Use case diagram dari sistem absensi yang terdapat gambar. Administrator adalah aktor utama dapat melakukan kegiatan seperti login, input data karyawan, data jabatan, data shift dan data lokasi penempatan kerja. Selain dapat menginput data, administrator juga dapat mengambil QR Code dari data karyawan yang telah dibuat dan melakukan scan QR Code sebagai absensi dan dapat melakukan rekapitulasi hasil absensi sehingga dapat dijadikan sebuah laporan kepada atasan instansi. Aktor kedua sebagai Karyawan hanya dapat melakukan login, scan QR Code, dan melihat beberapa data serta rekapitulasi absensi.

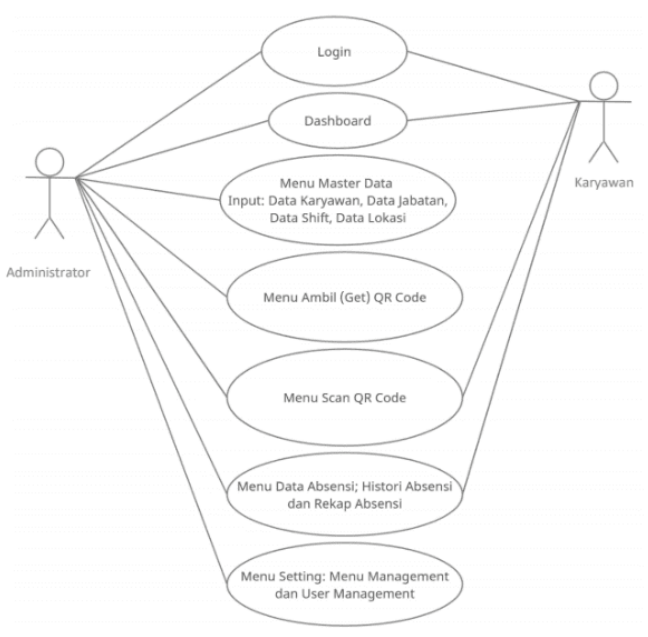

Gambar 1. Use Case Diagram

\section{Perancangan Basis Data}

Basis data yang terdiri dari user, menu, shift, gedung, presensi, kehadiran, karyawan serta relasi antar tabel.

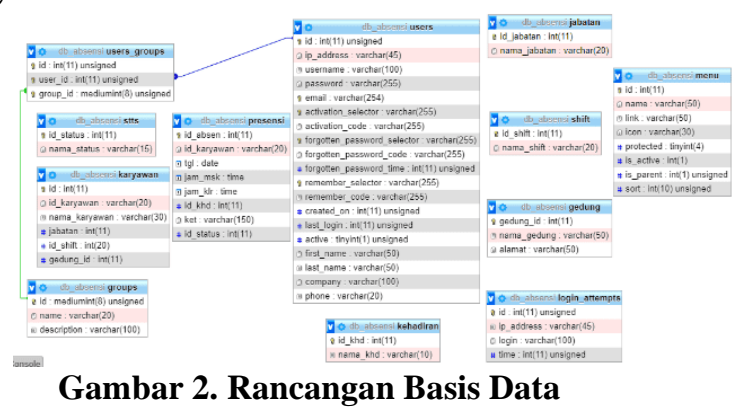

\section{Arsitektur Sistem}

Sistem Absensi dibuat dengan memiliki dua user, yaitu administrator dan karyawan yang hadir selama jam kerja. Sistem dapat melakukan cetak kartu identitas setiap karyawan dengan Kode QR yang dapat diperiksa untuk absensi kehadiran. Mendapatkan informasi kehadiran yang tepat, Kode QR akan mengambil data primary key dari setiap karyawan secara real time dengan scanning pada webcam. Data kehadiran yang didapat dari pemeriksaan dan tersimpan ke dalam database dan diproses untuk ditampilkan dalam rekapitulasi kehadiran (Puput et al., 2019). 


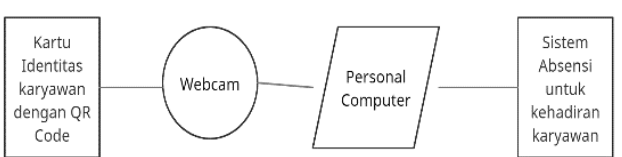

Gambar 3. Arsitektur Sistem

\section{Pengujian}

Absensi Karyawan dengan QR Code

Tahap pengujian dilakukan dengan menguji kinerja sistem oleh developer. Setelah melakukan pengujian sistem, selanjutnya mengisi penilaian dan saran tentang sistem.

1. Implementasi

Implementasi sistem ini diselesaikan dengan memanfaatkan bahasa pemrograman PHP dengan framework codeigniter melalui perangkat aplikasi Visual Studio Code dan Database untuk merancang basisdata MySQL sebagai tempat penyimpanan selama pembuatan dan perbaikan. Selanjutnya sistem dijalankan pada Personal Computer melalui browser seperti, Chrome, Mozilla Firefox, UC Browser, dan Opera Mini atau browser lainnya. Implementasi QR Code dilakukan dengan membuat data karyawan baru, setelah itu melakukan ambil QR Code pada sistem file image atau pdf pada kartu identitas perusahaan disetiap karyawan.

2. Perawatan

Perawatan dilakukan dengan tujuan agar sistem dapat berfungsi sesuai rancangan. Selain itu, perawatan dilakukan sehingga user dapat mengubah kebutuhan mereka jika terjadi perubahan atau persyaratan tambahan. Hal ini dilakukan agar user dapat memanfaatkan sistem dengan mudah. (Puput et al., 2019).

\section{Algoritma Vigenere Chiper}

Vigenère Cipher adalah algoritma ini menggunakan kunci dari bujursangkar Vigènere untuk melakukan enkripsi. Bagian kiri terjauh bujur sangkar membahas huruf-huruf kunci, sedangkan baris paling atas membahas huruf-huruf teks biasa. Jumlah huruf teks biasa yang bergerak ditentukan oleh nilai numerik dari huruf kunci (yaitu, $\mathrm{A}=0, \mathrm{~B}$ $=1, \mathrm{C}=2, \ldots, \mathrm{Z}=25)$ (Pratama \& Tamatjita, 2015).

Tabel 1. Bujursangkar Vigenere

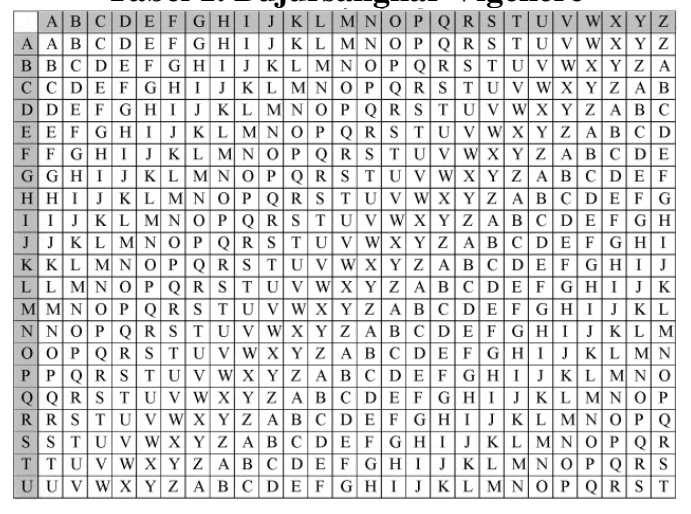

\section{HASIL DAN PEMBAHASAN}

\section{Penerapan Algoritma Vigenere Cipher pada QR Code}

Penerapan algoritma vigenere cipher pada sistem QR Code yang dirancang, dilakukan perhitungan vigenere cipher. Kasus enkripsi dan dekripsi tentang nama jabatan disetiap kartu identitas karyawan diwajibkan memberikan auto generate qr code identitas (Hasibuan et al., 2019).

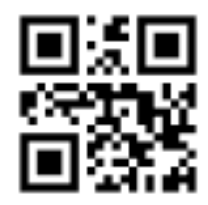

\section{Gambar 4. QR Code}

Perhitungan lebih dulu dilakukan membentuk tabel untuk mengganti setiap huruf, symbol dan angka dengan angka.

Tabel 2. Perubahan Huruf Menjadi Angka

\begin{tabular}{cccccccccc}
\hline $\mathrm{A}$ & $\mathrm{B}$ & $\mathrm{C}$ & $\mathrm{D}$ & $\mathrm{E}$ & $\mathrm{F}$ & $\mathrm{G}$ & $\mathrm{H}$ & $\mathrm{I}$ & $\mathrm{J}$ \\
\hline 0 & 1 & 2 & 3 & 4 & 5 & 6 & 7 & 8 & 9 \\
\hline $\mathrm{K}$ & $\mathrm{L}$ & $\mathrm{M}$ & $\mathrm{N}$ & $\mathrm{O}$ & $\mathrm{P}$ & $\mathrm{Q}$ & $\mathrm{R}$ & $\mathrm{S}$ & $\mathrm{T}$ \\
\hline
\end{tabular}




\begin{tabular}{cccccccccc}
\hline 10 & 11 & 12 & 13 & 14 & 15 & 16 & 17 & 18 & 19 \\
\hline $\mathrm{U}$ & $\mathrm{V}$ & $\mathrm{W}$ & $\mathrm{X}$ & $\mathrm{Y}$ & $\mathrm{Z}$ & 0 & 1 & 2 & 3 \\
\hline 20 & 21 & 22 & 23 & 24 & 25 & 26 & 27 & 28 & 29 \\
\hline 4 & 5 & 6 & 7 & 8 & 9 &. & & & \\
\hline 30 & 31 & 32 & 33 & 34 & 35 & 36 & & & \\
\hline
\end{tabular}

Perhitungan enkripsi dan dekripsi data pada QR Code huruf besar dan huruf kecil sama, tetapi saat program di implementasikan huruf besar dan huruf kecil akan dibedakan.

\section{Proses Perhitungan Enkripsi QR Code}

Proses enkripsi QR Code pada jabatan manajer, sebagai berikut:

Plaintext : Manajer $(\mathrm{M}=12, \mathrm{~A}=0$,

$\mathrm{N}=13, \mathrm{~A}=0, \mathrm{~J}=9, \mathrm{E}=4, \mathrm{R}=17$,)

Key : Absensi $(\mathrm{A}=0, \mathrm{~B}=1$,

$S=18, E=4, N=13, S=18, I=8$,

Jumlah Numerik:

$\mathrm{M}+\mathrm{A}=12+0=12, \mathrm{~A}+\mathrm{B}=0+1=1$,

$\mathrm{N}+\mathrm{S}=13+18=31, \mathrm{~A}+\mathrm{E}=0+4=4$,

$\mathrm{J}+\mathrm{N}=9+13=22, \mathrm{E}+\mathrm{S}=4+18=22$,

$\mathrm{R}+\mathrm{I}=17+8=25$,

Huruf Dari Hasil Jumlah Numerik:

$12=\mathrm{M}, 1=\mathrm{B}, 31=\mathrm{F}, 4=\mathrm{E}, 22=\mathrm{W}$,

$22=\mathrm{W}, 25=\mathrm{Z}$,

Ciphertext: MBFEWWZ

Proses enkripsi pada jabatan staff, sebagai berikut:

Plaintext : Staff $(S=18, T=19, A=0$, $\mathrm{F}=5, \mathrm{~F}=5$ )

Key : Absensi $(\mathrm{A}=0, \mathrm{~B}=1$, $\mathrm{S}=18, \mathrm{E}=4, \mathrm{~N}=13, \mathrm{~S}=18, \mathrm{I}=8$,

Jumlah Numerik:

$\mathrm{S}+\mathrm{A}=18+0=18, \mathrm{~T}+\mathrm{B}=19+1=20$,

$\mathrm{A}+\mathrm{S}=0+18=18, \mathrm{~F}+\mathrm{E}=5+4=9$,

$\mathrm{F}+\mathrm{N}=5+13=18$,

Huruf Dari Hasil Jumlah Numerik:

$18=$ S, $20=\mathrm{U}, 18=\mathrm{S}, 9=\mathrm{J}, 18=\mathrm{S}$,

Ciphertext: SUSJS

Proses Pehitungan Dekripsi QR Code

Proses dekripsi pada jabatan manajer, sebagai berikut:

Plaintext : Manajer $(M=12, A=0$, $\mathrm{N}=13, \mathrm{~A}=0, \mathrm{~J}=9, \mathrm{E}=4, \mathrm{R}=17$,)

Key : Absensi $(\mathrm{A}=0, \mathrm{~B}=1$,

$\mathrm{S}=18, \mathrm{E}=4, \mathrm{~N}=13, \mathrm{~S}=18, \mathrm{I}=8$,

Pengurangan Numerik:
$\mathrm{M}+\mathrm{A}=12-0=12, \mathrm{~A}+\mathrm{B}=0-1=-1$,

$\mathrm{N}+\mathrm{S}=13-18=-5, \mathrm{~A}+\mathrm{E}=0-4=-4$,

$\mathrm{J}+\mathrm{N}=9-13=-4, \mathrm{E}+\mathrm{S}=4-18=-14$,

$\mathrm{R}+\mathrm{I}=17-8=9$,

Huruf Dari Hasil Pengurangan

Numerik:

$12=\mathrm{M},-1=\mathrm{Z},-5=\mathrm{V},-4=\mathrm{W},-4=\mathrm{W},-$

14=M, 9=J,

Ciphertext: MZVWWMJ

Proses dekripsi pada jabatan staff, sebagai berikut:

Plaintext : Staff ( $S=18, T=19, A=0$, $\mathrm{F}=5, \mathrm{~F}=5$ )

Key : Absensi $(\mathrm{A}=0, \mathrm{~B}=1$,

$\mathrm{S}=18, \mathrm{E}=4, \mathrm{~N}=13, \mathrm{~S}=18, \mathrm{I}=8$,

Pengurangan Numerik:

$\mathrm{S}+\mathrm{A}=18-0=18, \mathrm{~T}+\mathrm{B}=19-1=18$,

$\mathrm{A}+\mathrm{S}=0-18=-18, \mathrm{~F}+\mathrm{E}=5-4=1$,

$\mathrm{F}+\mathrm{N}=5-13=-8$,

Huruf Dari Hasil Pengurangan

Numerik:

$18=\mathrm{S}, 18=\mathrm{S},-18=\mathrm{I}, 1=\mathrm{B},-8=\mathrm{S}$,

Ciphertext: SSIBS

\section{Desain User Interface}

Penelitian yang dilakukan menghasilkan sistem absensi karyawan dengan QR Code berbasis website. Sistem memudahkan setiap karyawan dalam melaksanakan absensi kehadiran. Sistem memiliki dua users, yaitu admin dan karyawan yang akan melakukan kegiatan absensi kehadiran.

\section{Halaman Login User}

Halaman login user adalah awal mula tampilan form setelah dilakukan pengetikan url link dari website sistem. Halaman awal berisi form Log In yang akan berfungsi untuk memproses validasi administrator dan karyawan agar dapat masuk ke halaman dashboard. 


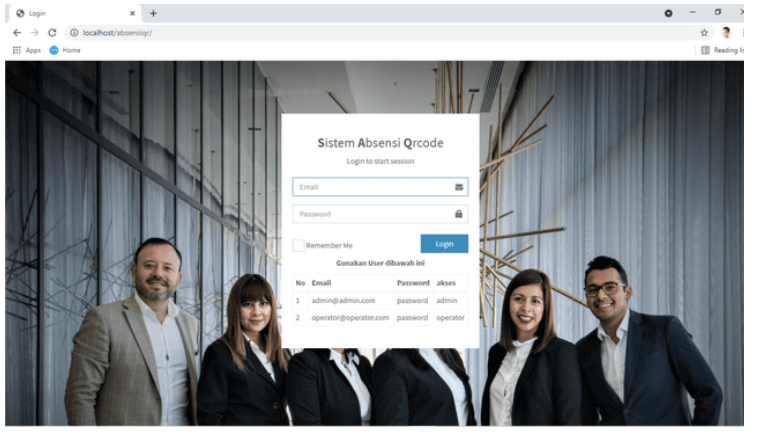

Gambar 5. Tampilan Awal (Login)

\section{Halaman Dashboard Admin dan Karyawan}

Halaman dashboard sebenarnya memiliki fungsi yang sama, yang membedakan admin dapat melakukan pembuatan, melihat, pengubahan dan penghapusan data (CRUD), serta melakukan absensi. Untuk karyawan hanya dapat membaca dan melakukan absensi saja.

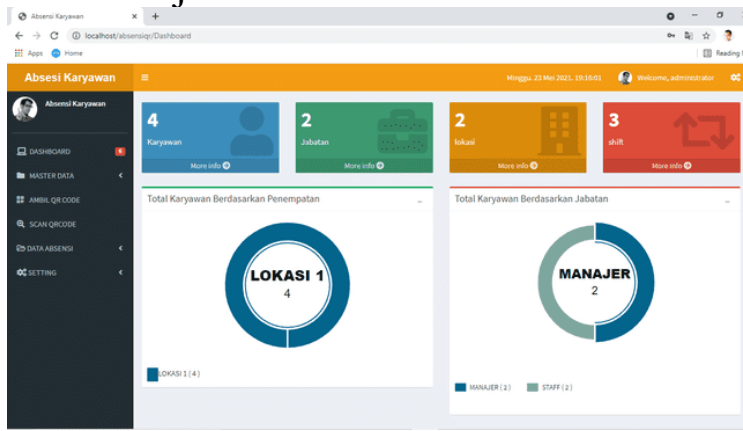

Gambar 6. Tampilan Dashboard Admin

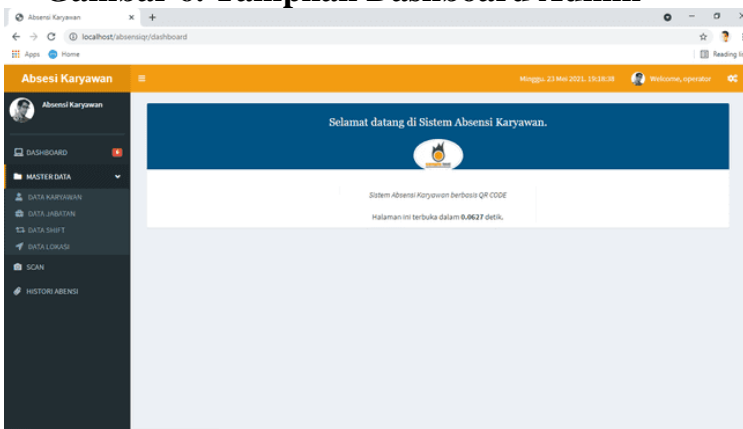

Gambar 7. Tampilan Dashboard Karyawan

\section{Halaman Menu Admin}

Dalam tampilan dashboard admin terdapat menu yang menampilkan halaman-halaman seperti, data karyawan, auto generate $Q R$ Code, scan $Q R$ Code, rekap absensi dan laporan. Tampilan data karyawan berisikan data karyawan yang ada pada perusahaan.

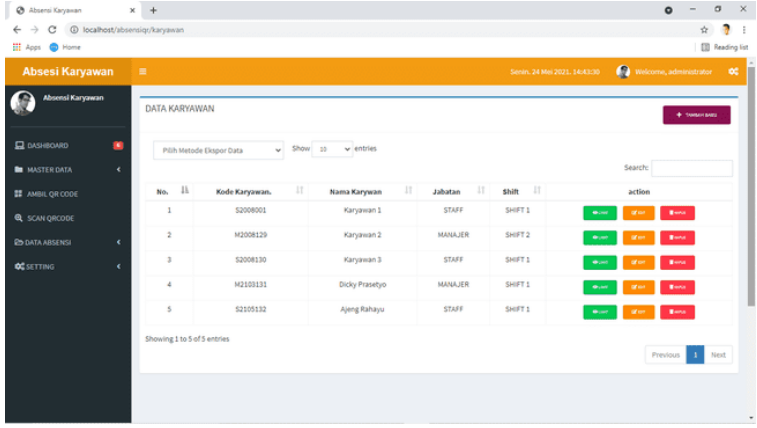

Gambar 8. Tampilan Menu Data Karyawan

Menu lain pada dashboard admin terdapat generate qr code. Admin akan melakukan pembuatan data baru pada karyawan yang nantinya akan dimasukkan ke dalam sistem absensi. Setelah data karyawan dibuat, admin akan menggenerate qr code serta nomor identitas dan menjadikannya kartu identitas, yang akan digunakan sebagai absensi kehadiran karyawan.

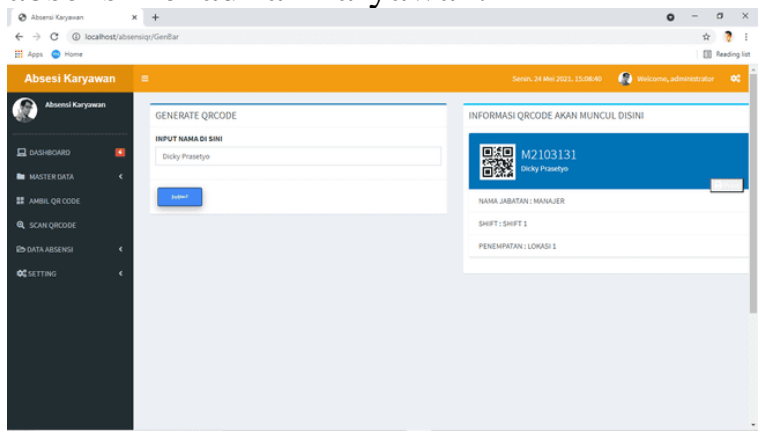

\section{Gambar 9. Tampilan Pada Menu Generate QR Code}

Menu lain yang ada dalam sistem absensi yaitu, scan $Q R$ Code yang berfungsi sebagai absensi pada sistem. Karyawan yang sudah memiliki kartu identitas dengan QR Code sudah bisa melakukan absensi secara online dengan mendekatkan kartu identitas yang terdapat QR Code ke webcam. Secara otomatis akan ada data kehadiran karyawan dan admin akan langsung mengecek dan melakukan pengubahan keterangan jam pulang kerja. 


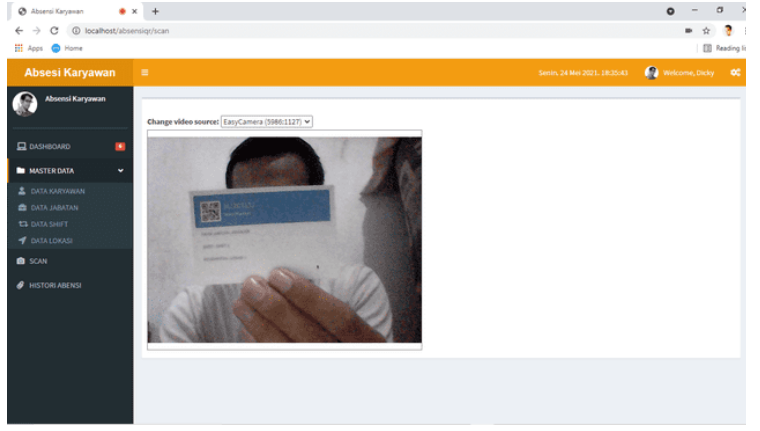

Gambar 10. Tampilan Scan QR Code

Halaman menu selanjutnya yaitu, rekap absensi dan laporan, dimana admin akan melakukan rekapitulasi data absensi dan membuat laporan untuk diserahkan kepada atasan. Dengan sistem absensi online ini membuat kehadiran menjadi lebih mudah dan admin selaku pengelola tidak kesulitan dalam melakukan tugasnya mengurus sistem kehadiran.

\section{Pengujian Aplikasi \\ Black Box Testing}

Hasil pengujian black box yang dilakukan membuktikan bahwa fitur dapat berjalan sesuai dengan rancangan.

Tabel 3. Hasil Uji Black Box

\begin{tabular}{llllrl}
\hline Menu & Komponen yang Diuji & Peranan yang diuji & Input & Output \\
\hline Log In & $\begin{array}{l}\text { Tampilan form username } \\
\text { dan password }\end{array}$ & $\begin{array}{l}\text { Username dan password yang } \\
\text { diinputkan oleh pengguna }\end{array}$ & $\begin{array}{l}\text { Username } \\
\text { password } \\
\text { sesuai }\end{array}$ & dang & Valid \\
& Log In & $\begin{array}{l}\text { Melakukan login ke sistem dan } \\
\text { masuk ke halaman dashboard }\end{array}$ & $\begin{array}{l}\text { Klik (button) Login } \\
\text { (bubol Valid }\end{array}$ &
\end{tabular}

Dashboard

Tabel 4. Lanjutan Hasil Pengujian Black Box

\begin{tabular}{|c|c|c|c|c|}
\hline Menu & $\begin{array}{l}\text { Komponen } \\
\text { yang Diuji }\end{array}$ & Peranan yang diuji & Input & Output \\
\hline \multirow{4}{*}{$\begin{array}{l}\text { Menu } \\
\text { Master } \\
\text { Data }\end{array}$} & $\begin{array}{l}\text { Sub-menu Data } \\
\text { Karyawan }\end{array}$ & $\begin{array}{l}\text { Tampilkan, Input, Read, Update } \\
\text { dan Delete Data Karyawan }\end{array}$ & $\begin{array}{l}\text { Pilih klik tombol tambah, lihat, } \\
\text { edit, dan hapus }\end{array}$ & Valid \\
\hline & $\begin{array}{l}\text { Sub-menu Data } \\
\text { Jabatan }\end{array}$ & $\begin{array}{l}\text { Tampilkan, Input, Read, Update } \\
\text { dan Delete Data Jabatan }\end{array}$ & $\begin{array}{l}\text { Pilih klik tombol tambah, lihat, } \\
\text { edit, dan hapus }\end{array}$ & Valid \\
\hline & $\begin{array}{l}\text { Sub-menu Data } \\
\text { Shift }\end{array}$ & $\begin{array}{l}\text { Tampilkan, Input, Read, Update } \\
\text { dan Delete Data Shift }\end{array}$ & $\begin{array}{l}\text { Pilih klik tombol tambah, lihat, } \\
\text { edit, dan hapus }\end{array}$ & Valid \\
\hline & $\begin{array}{l}\text { Sub-menu Data } \\
\text { Lokasi }\end{array}$ & $\begin{array}{l}\text { Tampilkan, Input, Read, Update } \\
\text { dan Delete Data Lokasi }\end{array}$ & $\begin{array}{l}\text { Pilih klik tombol tambah, lihat, } \\
\text { edit, dan hapus }\end{array}$ & Valid \\
\hline $\begin{array}{l}\text { Menu } \\
\text { QR Code }\end{array}$ & $\begin{array}{l}\text { Ambil Generate QR } \\
\text { Code }\end{array}$ & $\begin{array}{l}\text { Menampilkan Kartu } \\
\text { Identitas Karyawan beserta } \\
\text { QR Code }\end{array}$ & $\begin{array}{l}\text { Input nama karyawan, pilih } \\
\text { submit dan print kartu identitas }\end{array}$ & Valid \\
\hline
\end{tabular}




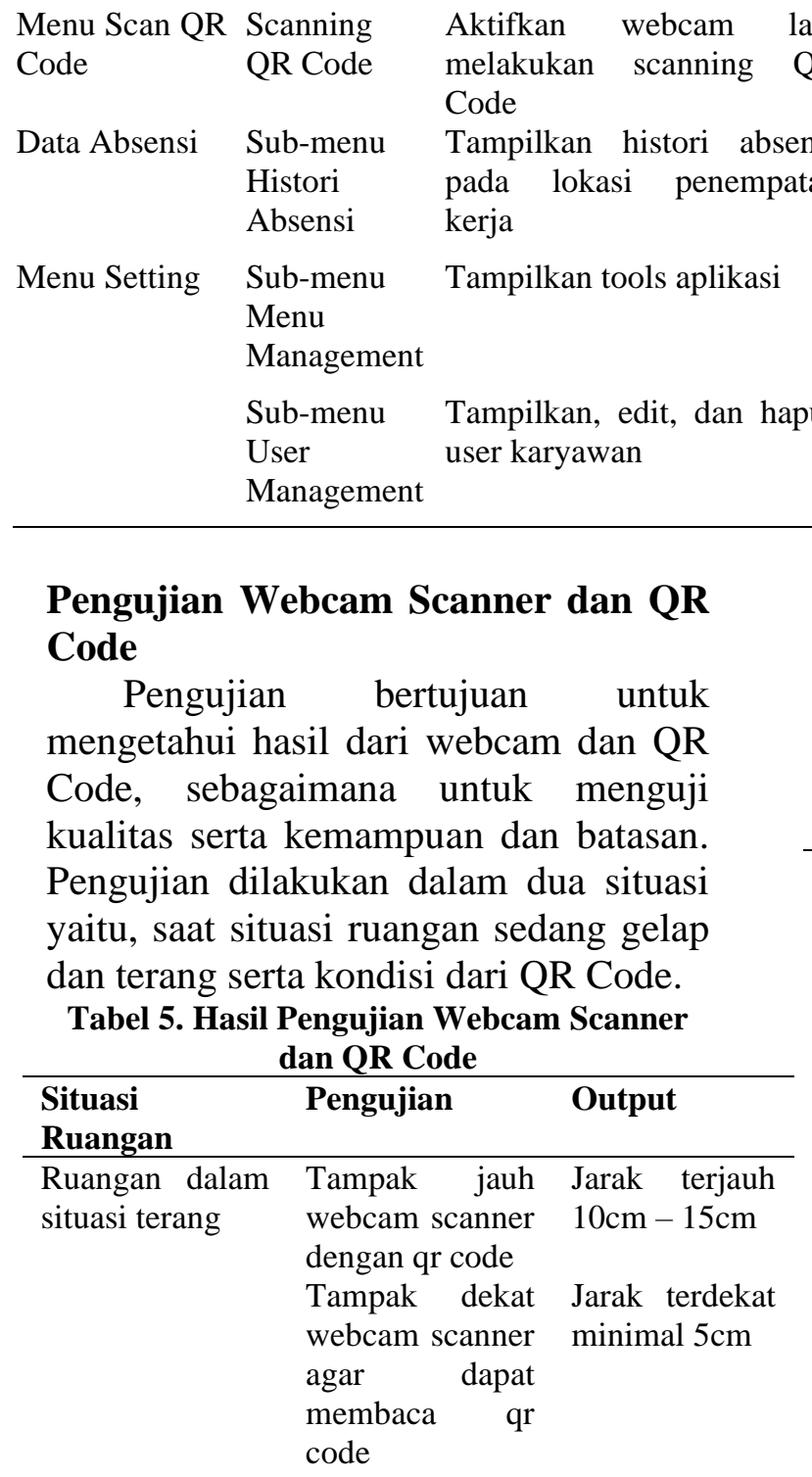

Ruangan dalam Jarak terjauh dan Jarak terjauh situasi gelap terdekat antara dan terdekat webcam scanner adalah $5 \mathrm{~cm}$ dengan qr code agar bisa membaca data $\mathrm{qr}$ code

Tinkat penerangan terbaik saat melakukan scan qr code

Kondisi Code QR Kondisi QR Code pada saat melakukan scanner harus dalam kondisi yang baik. Jika

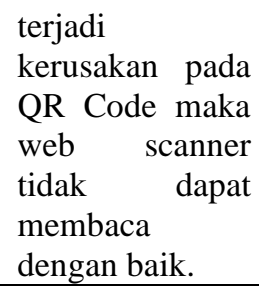

\section{SIMPULAN}

Sistem absensi berbasis web menggunakan kode qr adalah suatu pengembangan dari teknologi yang sudah ada dan sudah pernah dibuat sebelumnya. Kehadiran dalam suatu instansi merupakan hal yang penting, karena setiap instansi mewajibkan karyawan melakukan kehadiran sebagai prestasi kedisiplanan dalam bekerja. Oleh karena itu dirancanglah sistem kehadiran dalam bentuk online menggunakan kode qr serta dapat dilakukan dengan jarak jauh dimana sistem ditempatkan terpusat. Sistem memudahkan setiap pekerja dalam hal kehadiran dan tidak perlu banyak menggunakan lembar fisik atau manual untuk absensi kehadiran. Selain itu juga, sistem membantu pengelola dalam membuat rekapitulasi dan laporan data kehadiran para pekerja.

\section{DAFTAR PUSTAKA}

Hasibuan, A. Z., Asih, M. S., \& Harahap, H. (2019). Penerapan QR Code dan Vigenere Cipher Dalam Sistem Pelaporan Juru Parkir Ilegal. Jurnal 
Sistem Informasi.

Kumar, B. D., \& Kareemulla, S. (2017). Smart Mobile Attendance System for Employees Using QR Scanner. Asian Journal of Applied Science and Technology (AJAST).

Lengkong, O. H., Fiden, D. H., \& Masrikat, A. (2016). Sistem Informasi Absensi Real-Time di Universitas Klabat. CogITo Smart Journal.

https://doi.org/10.31154/cogito.v2i 2.31.216-228

Patel, A., Joseph, A., Survase, S., \& Nair, R. (2019). Smart Student Attendance System Using QR Code. SSRN Electronic Journal. https://doi.org/10.2139/ssrn.33707 69

Patta, A. R., \& Suhartono, S. (2017). PENGEMBANGAN SISTEM INFORMASI ABSENSI GURU DAN SISWA BERBASIS WEB DI SMA NEGERI 1 TELLULIMPOE KABUPATEN SINJAI. Jurnal Teknologi Elekterika. https://doi.org/10.31963/elekterika. v14i1.1216

Pratama, G. M., \& Tamatjita, E. N. (2015). MODIFIKASI ALGORITMA VIGENÈRE CIPHER MENGGUNAKAN METODE CATALAN NUMBER DAN DOUBLE COLUMNAR TRANSPOSITION. Compiler. https://doi.org/10.28989/compiler. v4i1.85

Puput, D., Putri, M., \& Supriyono, H. (2019). Rancang Bangun Sistem Presensi Berbasis QR Code Menggunakan Framework Codeigniter (Studi Kasus Kehadiran Asisten Praktikum). Insypro.

Rhomadhona, H. (2018). Penerapan Teknologi QR Code Berbasis Web untuk Absensi Pegawai pada BKPSDM Kabupaten Tanah Laut.
Jurnal Humaniora Teknologi. https://doi.org/10.34128/jht.v4i1. 